\title{
Implementation of An Outdoor Smoke-Free Policy at Sports Clubs: Critical Situations and Factors Influencing Implementation
}

Heike H Garritsen ( $\square$ h.h.garritsen@amsterdamumc.nl )

Amsterdam UMC https://orcid.org/0000-0003-4491-6814

Andrea D Rozema

Tilburg University Tranzo Scientific Centre for Care and Welfare

len $A M$ van de Goor

Tilburg University Tranzo Scientific Centre for Care and Welfare

Anton E Kunst

Amsterdam UMC

Research

Keywords: Implementation, smoke-free policy, outdoor, sports

Posted Date: September 2nd, 2020

DOI: https://doi.org/10.21203/rs.3.rs-67552/v1

License: (a) (i) This work is licensed under a Creative Commons Attribution 4.0 International License.

Read Full License 


\section{Abstract}

Background: Outdoor smoke-free policies (SFPs) at sports clubs have significant potential in reducing adolescent smoking. However, the actual occurrence of such effects may be strongly dependent on how these policies are implemented in practice. The aim of this study is to identify to what extent outdoor SFPs at sports clubs are implemented in practice and which factors contribute to successful implementation.

Methods: Semi-structured interviews were held with 46 key stakeholders at 8 Dutch sports clubs (i.e., field hockey, soccer, tennis, korfball) with an outdoor SFP. A thematic approach was used for analysis of the transcripts.

Results: Overall, the implementation of an outdoor SFP at sports clubs appears to be successful. The SFP is often enforced, smokers react positively when they are approached, the SFP has led to less (visible) smokers at the venue, and a nonsmoking norm is reinforced. However, we identified three 'critical situations' in which implementation is less than optimal: 1) when children are not present at the sports club, 2) when alcohol is involved, and 3) when smokers relocate at the entrance of the sports club. Several factors influenced implementation in those critical situations: 1) factors related to individual smokers and club members (i.e., support, communication towards smokers), 2) factors related to the SFP itself (i.e., clarity of the policy), 3) factors related to the sports club (i.e., communication of the policy, characteristics of the sports club), and 4) factors related to the wider community (i.e., change of social norm with regard to smoking, support from local and national organizations).

Conclusions: Successful implementation of an outdoor SFP at sports clubs is feasible since support is high and experiences are mainly positive. Nevertheless, some situations represent challenges to compliance and enforcement. We identified a number of factors through which sports clubs may foster effectively implementation of an outdoor SFP at their clubs.

\section{Contributions To The Literature}

- Since sports clubs are popular leisure-time settings for many adolescents, outdoor smoke-free policies at sports clubs have significant potential in reducing adolescent smoking.

- This study contributes to the literature by identifying how outdoor smoke-free policies at sports clubs are implemented in practice, and which factors contribute to successful implementation.

- Our findings and recommendations may help sports clubs to foster effective implementation of an outdoor smoke-free policy, and may be particularly useful to sports clubs that have not yet implemented such policy, but who feel encouraged to become smoke-free as well.

\section{Background}


Smoking is the single most preventable cause of death and disease (1). Early experimentation with cigarettes can have serious health consequences, as research shows that smoking a single cigarette in childhood is highly predictive of regular smoking later in life $(2,3)$. Europe has a high prevalence of tobacco use by adolescents. For example, an average of $46 \%$ of European students aged $15-16$ has smoked at least once in their lifetime, and $21 \%$ has smoked in the past 30 days (4). Because of this, early smoking prevention strategies are an important public health priority.

One way to establish healthy environments with regard to smoking is through the implementation of smoke-free policies (SFPs). SFPs reduce the visibility of smoking, limit the opportunities for adolescents to smoke, and communicate that smoking is socially unacceptable (5-7).

Besides SFPs that prohibit smoking in indoor public places (e.g. bars, restaurants), outdoor SFPs are being increasingly implemented (8). Outdoor SFPs prohibit smoking e.g. in parks, playgrounds, or at outdoor sports clubs. The latter have significant potential in reducing adolescent smoking since sports clubs are popular leisure-time settings for many adolescents. With $60 \%$ of $12-19$-year-old Dutch adolescents participating in organized sports (9), sports clubs have significant reach and potential for influence at the community level. In recent years, over 1500 sports clubs in the Netherlands have voluntarily implemented an outdoor SFP at their venues. Those SFPs vary from strict (prohibiting outdoor smoking at the entire venue, without exemptions) to partial (allowing exemptions, e.g. smoking is allowed on Sunday or in the evening).

It is important to understand whether, how, and under which circumstances an outdoor SFP at sports clubs is successful is protecting adolescents against smoking. While SFPs could have important protective effects in theory, the actual occurrence of such effects may be strongly dependent on how these policies are implemented in practice. Effects may be reduced, nullified, or even reversed if a policy is non-consistent, poorly communicated, or not enforced (10-12).

A few studies have explored the implementation of an outdoor SFP in the sports setting. However, these studies focused on general support for (13) or compliance with (14) an outdoor SFP, or focused on overall implementation of health-related policies in a sports setting and not on SFPs specifically (15).

This paper attempts to move the field forward by identifying how outdoor SFPs at sports clubs are implemented in practice, and which factors contribute to successful implementation. We did this by conducting semi-structured interviews with key stakeholders at different sports clubs in the Netherlands.

\section{Methods}

\section{Participants}

Eight Dutch sports clubs with a strict (i.e., without exemptions) outdoor SFP were included in the study. To represent the variety of outdoor sports clubs in the Netherlands, we included four major sports: soccer, tennis, field hockey, and korfball. Those four sports differ in characteristics. Field hockey is popular 
among families with high socioeconomic status (SES), while soccer players tend to come from lower-SES families. Tennis is both a team sport and an individual sport. Korfball teams consist of both boys and girls. In addition to variation in sports, we took into account variation between Dutch regions when selecting sports clubs. In total, 25 sports clubs were contacted face-to-face, by phone, e-mail, and/or letter and asked whether they would participate. Participating clubs $(n=8)$ did not differ substantially from the non-participating clubs $(n=17)$ in type of sports $(p=0.29)$ and level of urbanization $(p=0.74)$. The main reason for non-participation was lack of interest. Table 1 presents the characteristics of the participating sports clubs. 
Table 1

Characteristics of the participating sports clubs

\begin{tabular}{|c|c|c|c|}
\hline & \multicolumn{3}{|c|}{ No. of sports clubs } \\
\hline & $n=8$ & $\%$ & No. of respondents \\
\hline \multicolumn{4}{|l|}{ Sports } \\
\hline Soccer & 2 & 25.0 & 12 \\
\hline Korfball & 2 & 25.0 & 12 \\
\hline Field hockey & 2 & 25.0 & 11 \\
\hline Tennis & 2 & 25.0 & 11 \\
\hline \multicolumn{4}{|l|}{ Size } \\
\hline$<250$ members & 1 & 12.5 & 6 \\
\hline 250-500 members & 3 & 37.5 & 17 \\
\hline 500-1000 members & 3 & 37.5 & 17 \\
\hline 1000-1500 members & 1 & 12.5 & 6 \\
\hline \multicolumn{4}{|l|}{ Urbanity } \\
\hline Highly urbanized region & 2 & 25.0 & 11 \\
\hline Urbanized region & 3 & 37.5 & 18 \\
\hline Moderate urbanized region & 1 & 12.5 & 5 \\
\hline Rural region & 2 & 25.0 & 12 \\
\hline Highly rural region & 0 & 0.0 & 0 \\
\hline \multicolumn{4}{|c|}{ Year of implementation of outdoor SFP } \\
\hline 2017 & 3 & 37.5 & 18 \\
\hline 2018 & 4 & 50.0 & 23 \\
\hline 2019 & 1 & 12.5 & 5 \\
\hline
\end{tabular}

At each sports club, semi-structured interviews were held with key stakeholders (i.e., committee members, board members, trainers/coaches, parents, referees, and other stakeholders). Variation according to gender, function within the sports club, and smoking status were taking into account during recruitment of the stakeholders. A total of 46 respondents participated in the study. Their mean age was 48.13 years $(S D=16.01)$ (range 20-77). Table 2 presents the characteristics of the respondents. 
Table 2

Characteristics of the respondents

No. of respondents

$\mathrm{n}=46 \quad \%$

\section{Gender}

Male

32

69.6

Female

14

30.4

Function $^{a}$

Committee member ${ }^{b}$

20

43.5

Board member

14

30.4

Trainer/coach

11

23.9

Parent

4

8.7

Arbitrator

3

6.5

Other ${ }^{\mathrm{c}}$

2

4.3

\section{Smoking status ${ }^{d}$}

Smoker

Non-smoker
4

42
8.7

91.3

a. Total numbers in row do not add up to 46 as some respondents had multiple functions within the sports club

b. Includes members from different committees, such as the bar committee, technical committee, youth committee, tournament committee and party committee

c. Website builder and team captain

d. Smoker refers to daily smokers; non-smoker refers to non-daily smokers and non-smokers

\section{Procedure}

The study was conducted (2019-2020) in collaboration with Sportief Advies (SA), a Dutch organization that supports projects with regard to sports and culture. SA was responsible for recruiting the sports clubs and conducting the interviews. Three employees of SA were instructed in data collection by the first, second, and last author (HHG, ADR, AEK).

Semi-structured interviews were held with key stakeholders to explore their perceptions with respect to the implementation of an outdoor SFP. Based on two widely used implementation frameworks $(16,17)$, we 
identified factors to be included in the initial interview guide to explore issues relevant to implementation), see Appendix 1. Gender, age, function within the sports club, and smoking status of the respondents were noted. Furthermore, sports club size, urbanization level, and year of implementation of the outdoor SFP were noted. All respondents signed an informed consent form and data were recorded on a digital audiorecorder. Interviews lasted on average 24 minutes (range 13-37). The Medical Ethics Review Committee of the Academic Medical Center confirmed that the Dutch Medical Research Involving Human Subjects Act (WMO) did not apply to this study and that an official approval was not required (W20_318 \# 20.369).

\section{Analysis}

Interviews were transcribed verbatim and analyzed using MAXQDA (18). Thematic analysis, a qualitative analytic method for identifying, analyzing and reporting patterns (themes) within data, was used (19). Within this thematic analysis, an inductive (or 'bottom up') way was chosen. The coding was conducted by the first author ( $\mathrm{HHG}$ ). To establish inter-rater reliability, another researcher coded in parallel $33 \%$ of all transcripts. Inconsistencies regarding codes were discussed until consensus was reached. Thereafter, similar codes were pooled and overarching themes were created based on the final code list. These themes were classified into "critical situations" and "factors influencing implementation". The appropriateness and classification of the developed themes were discussed with all authors and amended when judged necessary. Finally, the factors influencing implementation were broken down into categories, based on the same frameworks that have been used to develop the interview guide $(16,17)$.

\section{Results}

Overall, implementation of an outdoor SFP at sports clubs appears to be successful. First, the SFP has led to less (visible) smokers at the venue. Some respondents mentioned that they cannot even remember the last time they saw someone smoking at their club. Second, the SFP is often actively enforced, and most of the time smokers react positively when they are approached. Finally, a nonsmoking norm is reinforced, i.e., according to respondents, smoking at the sports club is no longer seen as 'normal'.

"Interviewer: Do people still smoke at the sports club? Respondent: Very occasionally. I can't even remember the last time in weeks." (Respondent 50, field hockey).

Nevertheless, a number of situations in which implementation is less than optimal, i.e., critical situations, emerged from the data analysis. In addition, we identified a number of factors that can foster or hinder successful implementation in such situations.

\section{Critical situations}

Three critical situations with regard to the implementation of an outdoor SFP were identified: 1) when children are not present at the sports club, 2) when alcohol is involved, and 3) when smokers relocate to the entrance of the sports club. 


\section{When children are not present at the sports club}

When (almost) no children are present at the sports clubs, i.e., in the evening, on Sunday, or during parties or events at the sports club, support for and compliance with the SFP decreases. According to respondents, the reason for this is that the argument for nonsmoking, i.e., setting a good example for children, no longer applies. Given that argument, people find it hard to understand why they are not allowed to smoke and consider it exaggerated to not be allowed to smoke when children are no longer around.

"But when it's the end of the day and all children are gone, why can't I just have a smoke outside? I think that's their main issue." (Respondent 42, korfball).

In addition, the SFP is less enforced when children are not present at the sports club. Some respondents mentioned that the presence/absence of children determines whether they approach smokers or not.

\section{When alcohol is involved}

When alcohol is involved, smokers tend to comply less with the SFP. Respondents described how people smoke when they are having a good time together while drinking a beer, especially in the evening and during parties or events at the sports club. In addition, enforcement of the SFP is more challenging under those circumstances. People feel uncomfortable to approach smokers that consumed a lot of/ alcohol, as they expect to be faced with resistance or even aggression.

"It's hard when you see a group of drunk supporters smoking. You don't want to end up in all kind of aggressive discussions." (Respondent 6, soccer).

\section{When smokers relocate to the entrance of the sports club}

As a result of the outdoor SFP, large groups of people frequently gather at the entrance of the sports club to smoke. Consequently, smoking is still visible, and perhaps even more than before implementation of the SFP. According to respondents, children are literally walking through a 'hedge of smoke'. This is perceived as an undesirable side effect of the SFP, since the main goal of the SFP is to decrease smoking visibility and exposure.

"Literally, everyone stands in front of the fence. That's where all children walk in and out. On a busy afternoon, many people smoke there. So, to say that children stay completely out of range... no, actually not." (Respondent 5, soccer).

Respondents mentioned that they find it hard to approach people who smoke at the entrance of the sports club since this is perceived as public space and not part of the sports club's venue.

\section{Factors that contribute to successful implementation}

We identified seven factors that contribute to successful implementation, including its enforcement in the critical situations described above (see Fig. 1). These are 1) factors related to individuals (i.e., support, 
communicating with smokers), 2) factors related to the SFP itself (i.e., formulation of the policy), 3) factors related to the sports club (i.e., communication of the policy, characteristics of the sports club), and 4) factors related to the wider community (i.e., change of social norm with regard to smoking, support from local and national organizations).

\section{Factors related to individuals}

\subsection{Support}

The extent to which people support the SFP in practice is important since little support may cause resistance and lead to weak enforcement in "difficult" situations. According to respondents, most people support the SFP, including smokers. Most of them support the implementation of SFP in situations when children are present at the sports club, as most people agree that smoking around children is inappropriate and that children should be protected from the harmful effects of secondhand smoke. However, not everyone supports the SFP unconditionally. Especially hardcore smokers and older people sometimes feel patronized by the policy. As elderly have been a member of the sports club for a long time and, they feel that they have certain 'acquired rights'.

"Older people had more difficulty with that [implementation of the outdoor SFP] than the younger generation. You have a kind of acquired rights, like why do I suddenly have to leave the venue to smoke?" (Respondent 26, tennis).

To increase support for the SFP, some sports clubs actively involved club members most affected by the SFP (e.g. smokers) in the implementation of these policies. This helped to ensure that everyone embraced the proposed changes, and avoided resistance against the SFP. Respondents mentioned that "once you have the hardest people on board, the rest will follow".

\subsection{Communicating with active smokers}

According to respondents, the way in which club members deal with people who are smoking is important for successful enforcement of the SFP. One should approach smokers respectfully and use clear arguments to explain why smoking is not allowed. Respondents mentioned that framing the outdoor SFP as 'smoke-free' instead of 'a smoking ban' fosters a positive response. Similarly, a positive response is generally experienced when using the argument of association with 'children'.

"I've noticed that when I explain the policy in terms of children, everyone accepts it. Everyone knows someone with children, or is a grandfather or grandmother itself." (Respondent 5, soccer).

Commonly, people find it feasible to approach active smokers and ask them to stop. Respondents mentioned how a good atmosphere, people knowing each other, and mutual acceptance contribute to a generally favorable response. However, in some specific situations, people do find it difficult to approach active smokers. First, people sometimes perceive a higher risk of ending up in a discussion or conflict with smokers. According to them, then, "it is not worth the fight". Second, people find it hard to approach 
smokers who are older than themselves. They feel like they will not be taken seriously and expect older people to react negatively, saying they should mind their own business.

\section{Factors related to the SFP itself}

\subsection{Formulation of the policy}

Effective implementation of a SFP may be frustrated if the policy is not clearly formulated. At some sports clubs, the precise rules with regard to smoking are unclear (i.e., when/where is smoking allowed). This often leads to confusion and makes it more challenging to deal with active smokers. In addition, guidelines on how to approach active smokers often do not exist. Finally, often, it is not specified who is responsible for enforcement (i.e., the board, a small group of volunteers, or all club members), with the result that no one takes responsibility for the enforcement of the SFP.

"There is no supervision. When someone smokes, nobody is saying: "Hey, you can't smoke here". We need to make an agreement about that. Like: this is how we're going to do it." (Respondent 2, soccer)

\section{Factors related to the sports club}

\subsection{Communication of the policy}

According to respondents the majority of members is familiar with the smoking rules at their sports club. Sports clubs have used signs, posters, and/or banners to inform about the SFP, they have placed information about the SFP on their website, or they have sent a newsletter to all members of the sports club. According to respondents, such communication is important not only to avoid confusion and misunderstanding, but also to facilitate enforcement since it is easier for members to approach active smokers when they can point at a sign.

"When people are increasingly confronted with the rules, it will be much easier to approach smokers. After all, the only thing you'd have to say is: "Look at that sign"." (Respondent 12, korfball).

Other than members, visitors (e.g. supporters from other sports clubs) are often unknown with the SFP rules, especially when their own sports club does not have an outdoor SFP. This results in supporters reacting somewhat confused when they are asked to not smoke in the open air. Signs, posters, and banners are an important to deal with such situations as well.

\subsection{Characteristics of the sports club}

Certa9j characteristics of a sports club were reported to facilitate implementation of an outdoor SFP. First, having a small venue makes it easy to detect any smokers as it is more difficult for people to smoke out of sight. Second, having only few members who smoke may facilitate implementation of the SFP as nonsmoking was already more or less the norm.

"Hardly anyone smokes here, which probably makes it a lot easier for a sports club to implement a SFP. When half of your members smokes, it will be much more difficult." (Respondent 40, korfball). 
On the other hand, implementation is perceived as more difficult when sports clubs are situated at a sports park with several other sports clubs. It may be confusing to clubs' members and visitors when the other clubs do not have the same rules with regard to smoking.

\section{Factors related to the community}

\subsection{Change of social norm with regard to smoking}

Respondents mentioned how they perceive that the national social norm with regard to smoking is changing: the overall number of people who smoke is perceived to decline, Dutch smoke-free legislation is applied to increasingly more settings, and smoking is not socially accepted in ever more situations. Together, these changes make it easier to implement an outdoor SFP at sports clubs, to the extent that smokers have become used to the fact that they are not allowed to smoke in any place. In addition, their experience that other sports clubs have an outdoor SFP helps to increase acceptance of such policy since club members have already become familiar with this type of policies.

"We have the advantage that many of our members participate in two sports. That way, they are already used to SFPs at sports clubs." (Respondent 24, tennis).

\subsection{Support from local and national organizations}

Respondents emphasized the importance of support from both local and national organizations to implementing an outdoor SFP. On the local level, municipalities could support sports clubs by informing them on how to successfully implement and enforce the SFP. Furthermore, some respondents argued that municipalities could foster implementation by developing smoke-free regulations that apply to all sports clubs in the community. Similarly, on the national level, sports federations could also offer help by informing clubs or develop smoking smoke-free regulations that apply to all sports clubs. Respondents also argued that the government could make implementation much easier when smoking at sports clubs is prohibited by law.

"Just making a law. 'At these venues smoking is no longer allowed and that's it'. That way, all discussions are gone. In my opinion, that is eventually most effective." (Respondent 12, korfball).

\section{Discussion}

\section{Key findings}

The aim of the present study was to identify how outdoor SFPs at sports clubs are implemented in practice and which factors contribute to successful implementation. Respondents said that implementation of an outdoor SFP resulted in less smoking at the sports club and strengthening of a nonsmoking norm. The SFP is often actively enforced, and most of the time, smokers react positively when being approached. On the other hand, we identified three critical situations in which implementation is challenging: 1) when children are not present at the sports club, 2) when alcohol is involved, and 3) 
when smokers relocate at the entrance of the sports club. Finally, seven factors that contribute to successful implementation were identified: 1 ) factors related to individuals (i.e., support, communication towards smokers), 2) factors related to the SFP itself (i.e., formulation of the policy), 3) factors related to the sports club (i.e., communication of the policy, characteristics of the sports club), and 4) factors related to the wider community (i.e., change of social norm with regard to smoking, support from local and national organizations).

\section{Interpretation of findings}

We found that compliance to the SFP was problematic when (almost) no children were present at the sports club. This is in line with previous studies that found a strong relationship between support for an outdoor SFP and the presence of children at the target areas $(13,20)$. Thomson et al. $(21)$ found that setting an example to children is perceived as a strong reason for smokers to quit smoking, even more than concerns about their own health. We found that people may start smoking at sports clubs as soon as children are no longer present, arguing that the reason for nonsmoking has disappeared. However, although children are not around at the time people smoke, smoking can leave cues such as filled ash trays that can be a trigger for children to think about smoking (22).

Implementation and enforcement of the SFP was found to be more difficult when alcohol is involved, since people who smoke and drink at the same time may comply less with the SFP and may be harder to approach. Sports participation is related to high levels of alcohol consumption, particularly in team sports (23-27). The latter is likely due to the fact that drinking at club level is very much centered on team socializing and bonding (25). Therefore, health promotion at sports clubs may need to address smoking and alcohol use simultaneously. For example, the main Dutch organization for organized sports (NOC*NSF) has a national program aimed to create a 'Healthy Sport Environment' that addresses both smoking and problematic alcohol use (28).

We found that the introduction of an outdoor SFP has led to a relocation of active smokers to the entrance of the sports club. This finding has been reported in settings other than sports clubs as well (29-31). Smokers who congregate at the entrance expose non-smokers who enter and exit the sports club to secondhand smoke (SHS). There is no safe level of SHS (32) and concentrations of tobacco smoke at entrances can reach hazardous levels $(33,34)$. In addition, smoking at the entrance may contribute to negative role modelling and give a poor image to outsiders and visitors (35). Therefore, in addition, it may very well lead to the encouragement of smoking among adolescents.

The three critical situations that we identified show that smoking may still be tolerated despite the SFP. Studies in different settings than sports clubs have shown that such situations may arise particularly when SFPs policies have exemptions, as such policies may be interpreted as more lenient, prompting smokers to ignore the policy (36). Several studies have reported that SFPs are more effectively implemented only if exemptions are not tolerated (36-38).

\section{Study limitations}


Two limitations should be considered when interpreting the results. First, it is unclear whether the sports clubs included in this study are representative for all sports clubs in the Netherlands. Although we succeeded in including a large and diverse group of sports, regions, and stakeholders, the small number of clubs included limits generalizability of the results. Second, some social desirability bias might have occurred as board members may have been tempted to create a favorable image of their sports club. However, we found that all respondents, including board members, talked very openly about both positive and negative experiences.

\section{Implications}

Several implications derive from our findings. First, to be effective, SFPs at sports clubs need to be comprehensive, without exemptions. Smoking should not be tolerated when children are not present at the sports clubs. Second, possibilities should be investigated to extend the SFP to the entrance of the venue. For this, sport clubs may need to work together with municipalities or other parties with the authority to prohibit smoking. Third, sports clubs need to set up a thorough implementation strategy, including clear rules (specifying when and where smoking is not allowed, and who is responsible for enforcement), communication (including no-smoking signage), and advice on members on how to approach active smokers, particularly in difficult situations. Finally, municipalities and sports federations should support clubs in the formulation and implementation of an outdoor SFP, and stimulate a more general policy of 'healthy sports clubs' in which both smoking and alcohol use are tackled.

\section{Conclusions}

Successful implementation of an outdoor SFP at sports clubs appears very well feasible. Support among members is high and experiences with implementation are mainly positive. Nevertheless, some challenges are faced as well, especially with regard to compliance and enforcement. To further improve effective implementation, sports clubs should pay special attention to the critical situations identified in this study. The factors that contribute to successful implementation may help sports clubs to foster effective implementation of an outdoor SFP at their club. Our findings may be particularly useful to sports clubs that have not yet implemented an outdoor SFP, but who may feel encouraged to become smoke-free as well.

\section{Abbreviations}

SES

socioeconomic status

SHS

secondhand smoke

SFP

smoke-free policy 


\section{Declarations}

\section{Ethics approval and consent to participate}

The Medical Ethics Review Committee of the Academic Medical Center confirmed that the Dutch Medical Research Involving Human Subjects Act (WMO) did not apply to this study and that an official approval was not required (W20_318 \# 20.369).

\section{Consent for publication}

All respondents signed an informed consent form.

\section{Availability of data and materials}

The datasets used and analyzed during the current study are available from the corresponding author on reasonable request.

\section{Competing interests}

The authors declare that they have no competing interests.

\section{Funding}

This study was funded by ZonMw (project number 531003016).

\section{Authors' contributions}

HHG coded, analyzed, and interpreted the data, and wrote the manuscript. ADR, LAM, and AEK helped with interpretation and made substantively contributions to writing the manuscript. All authors read and approved the final manuscript.

\section{Acknowledgements}

Not applicable.

\section{References}

1. World Health Organization. Tobacco. Data and statistics. 2020. https://www.euro.who.int/en/healthtopics/disease-prevention/tobacco/data-and-statistics. Accessed May 192020.

2. Hilland TA, Beynon CM, McGee CE, Murphy RC, Parnell D, Romeo-Velilla M, et al. Training sports coaches to tackle tobacco: formative evaluation of the SmokeFree Sports campaign. Int $\mathrm{J}$ Health Promot Educ. 2015;53:2-16.

3. Nutys PAW, Kuipers MAG, Willemsen MC, Kunst AE. Trends in age of smoking initiation in the Netherlands: a shift towards older ages? Addiction. 2018;113:524-32. 
4. Group E. Results from the European school survey project on alcohol and other drugs. ESPAD Report.

5. Alesci NL, Forster JL, Blaine T. Smoking visibility, perceived acceptability, and frequency in various locations among youth and adults. Prev Med. 2003;36:272-81015.

6. Eisenberg ME, Forster JL. Adolescent smoking behavior: measures of social norms. Am J Prev Med. 2003;25:122-8.

7. Wakefield M, Forster J. Growing evidence for new benefit of clean indoor air laws: reduced adolescent smoking. Tob Control. 2005;14:292-3.

8. World Health Organization. Global progress report on implementation of the WHO Framework Convention on Tobacco Control. 2018. https://www.who.int/fctc/reporting/WHO-FCTC2018_global_progress_report.pdf?ua=1. Accessed 24 April 2020.

9. Van der Poel H, Hoeijmakers R, Pulles I, Tiesssen-Raaphorst A. Rapportage sport. 2018. https://www.scp.nl/publicaties/monitors/2018/12/12/rappor tage-sport-2018. Accessed May 7 2020.

10. Durlak JA, DuPre EP. Implementation matters: a review of research on the influence of implementation on program outcomes and the factors affecting implementation. Am J Community Psychol. 2008;41:327-50.

11. Jancey J, Bowser N, Burns S, Crawford G, Portsmouth L, Smith J. No smoking here: examining reasons for noncompliance with a smoke-free policy in a large university. Nicotine Tob Res. 2014;16:976-83.

12. Rozema AD, Hiemstra M, Mathijssen JJP, Jansen MWJ, van Oers H. Impact of an outdoor smoking ban at secondary schools on cigarettes, e-cigarettes and water pipe use among adolescents: an 18month follow-up. Int J Environ Res Public Health. 2018;15(2)

13. Thomson G, Wilson N, Edwards R. At the frontier of tobacco control: a brief review of public attitudes toward smoke-free outdoor places. Nicotine Tob Res. 2009;11:584-90.

14. Pikora T, Phang JW, Karro J, Corti B, Clarkson J, Donovan RJ, et al. Are smoke-free policies implemented and adhered to at sporting venues? Aust N Z J Public Health. 1999;23:407-9.

15. Dobbinson SJ, Hayman JA, Livingston PM. Prevalence of health promotion policies in sports clubs in Victoria, Australia. Health Promot Int. 2006;21:121-9.

16. Damschroder LJ, Aron DC, Keith RE, Kirsh SR, Alexander JA, Lowery JC. Fostering implementation of health services research findings into practice: a consolidated framework for advancing implementation science. Implement Sci. 2009;4:50.

17. Fleuren $M$, Wiefferink $K$, Paulussen $T$. Determinants of innovation within health care organizations: literature review and Delphi study. Int J Qual Health Care. 2004;16:107-23.

18. VERBI Software. MAXQDA Analytics Pro. Berlin: VERBI; 2020.

19. Braun V, Clarke V. Using thematic analysis in psychology. Qual Res Psychol. 2006;3:77-101.

20. Thomson G, Wilson N, Collins D, Edwards R. Attitudes to smoke-free outdoor regulations in the USA and Canada: a review of 89 surveys. Tob Control. 2016;25:506-16. 
21. Thomson G, Wilson N, Weerasekera D, Edwards R. Strong smoker interest in 'setting an example to children'by quitting: national survey data. Aust N Z J Public Health. 2011;35:81-4.

22. Schuck K, Otten R, Engels, RC, Kleinjan M. The role of environmental smoking in smoking-related cognitions and susceptibility to smoking in never-smoking 9-12 year-old children. Addict Behav. 2012;37:1400-1405.

23. Martens MP, Watson JC, Beck NC. Sport-type differences in alcohol use among intercollegiate athletes. J Appl Sport Psychol. 2006;18:136-50.

24. Wichstrøm T, Wichstrøm L. Does sports participation during adolescence prevent later alcohol, tobacco and cannabis use? Addiction. 2009;104:138-49.

25. Brenner J, Swanik K. High-risk drinking characteristics in collegiate athletes. J Am Coll Health. 2007;56:267-72.

26. Peretti-Watel P, Beck F, Legleye S. Beyond the U-curve: the relationship between sport and alcohol, cigarette and cannabis use in adolescents. Addiction. 2002;97:707-16.

27. Lorente FO, Souville M, Griffet J, Grélot L. Participation in sports and alcohol consumption among French adolescents. Addict Behav. 2004;29:941-6.

28. VWS. Nationaal Preventieakkoord: naar een gezonder Nederland. 2018. https://www.rijksoverheid.nl/onderwerpen/gezondheid-enpreventie/documenten/convenanten/2018/11/23/nationaal-preventieakkoord. Accessed May 12 2020.

29. 29. Nagle AL, Schofield MJ, Redman S. Smoking on hospital grounds and the impact of outdoor smoke-free zones. Tob Control. 1996;5:199-204.

30. Watts AW, Lovato CY, Card A, Manske SR. Do students' perceptions of school smoking policies influence where students smoke? Canada's Youth Smoking Survey. Cancer Cause Control. 2010;21:2085-92.

31. Rozema AD, Mathijssen JJ, van Oers HA, Jansen MW. Evaluation of the process of implementing an outdoor school ground smoking ban at secondary schools. J School Health. 2018;88:859-67.

32. World Health Organization. Air quality guidelines for Europe. 2000. https://www.euro.who.int/en/publications/abstracts/air-quality-guidelines-for-europe. Accessed June 22020.

33. Sureda X, Martínez-Sánchez JM, López MJ, Fu M, Agüero F, Saltó E, et al. Secondhand smoke levels in public building main entrances: outdoor and indoor PM2. 5 assessment. Tob Control. 2012;21:5438.

34. Sureda X, Fernández E, López MJ, Nebot M. Secondhand tobacco smoke exposure in open and semiopen settings: a systematic review. Environ Health Perspect. 2013;121:766-73.

35. Parry $\mathrm{O}$, Platt $\mathrm{S}$, Thomson $\mathrm{C}$. Out of sight, out of mind: workplace smoking bans and the relocation of smoking at work. Health Promot Int. 2000;15:125-33. 
36. Schreuders M, Nuyts PA, van den Putte B, Kunst AE. Understanding the impact of school tobacco policies on adolescent smoking behaviour: a realist review. Soc Sci Med. 2017;183:19-27

37. Wakefield MA, Chaloupka FJ, Kaufman NJ, Orleans CT, Barker DC, Ruel EE. Effect of restrictions on smoking at home, at school, and in public places on teenage smoking: cross sectional study. Bmj. 2000;321:333-7.

38. Gonzalez M, Glantz SA. Failure of policy regarding smoke-free bars in the Netherlands. Eur J Public Health. 2013;23:139-45.

\section{Appendix 1}

1. How would you describe the sports club?

2. How has the smoke-free policy been implemented at your sports club?

2.a. What was the reason to implement the policy?

2.b. Did the members of the sports club have a say in this?

2.c. How was the new policy communicated to the members?

3. What rules does this sports club have for smoking on the sports grounds?

3.a. Where do these rules apply?

3.b. When do these rules apply?

3.c. To whom do these rules apply?

3.d. What are the rules at parties, tournaments, or other events?

3.e. What are the rules for the e-cigarette?

4. To what extent are the rules clear to members of this sports club?

5. To what extent are the rules clear to visitors?

6. How can one know what the rules are?

7. To what extent do people coply with the smoke-free policy?

7.a. When do people smoke?

7.b. Where do people smoke?

7.c. Who is smoking? 
8. What happens if someone smokes?

8.a. Can you describe this situation?

8.b. Who is responsible?

8.c. How does the smoker react on this?

8.d. What do you do when you see someone smoking?

9. What hinders enforcement of the smoke-free policy?

9.a. Are there other things that hinder enforcement?

9.b. Are there other things?

NB: Keep on asking questions until all factors have been identified

10. What facilitates enforcement of the smoke-free policy?

10.a. Are there other things that facilitate enforcement?

10.b. Are there other things?

NB: Keep on asking questions until all factors have been identified

11. Which parties outside the sports club have influence on the smoking policy of a sports club?

11.a. Can you explain this?

11.b. Are there more parties important, besides party X?

11.c. Are there more parties important?

NB: Keep on asking questions until all factors have been identified

\section{Figures}




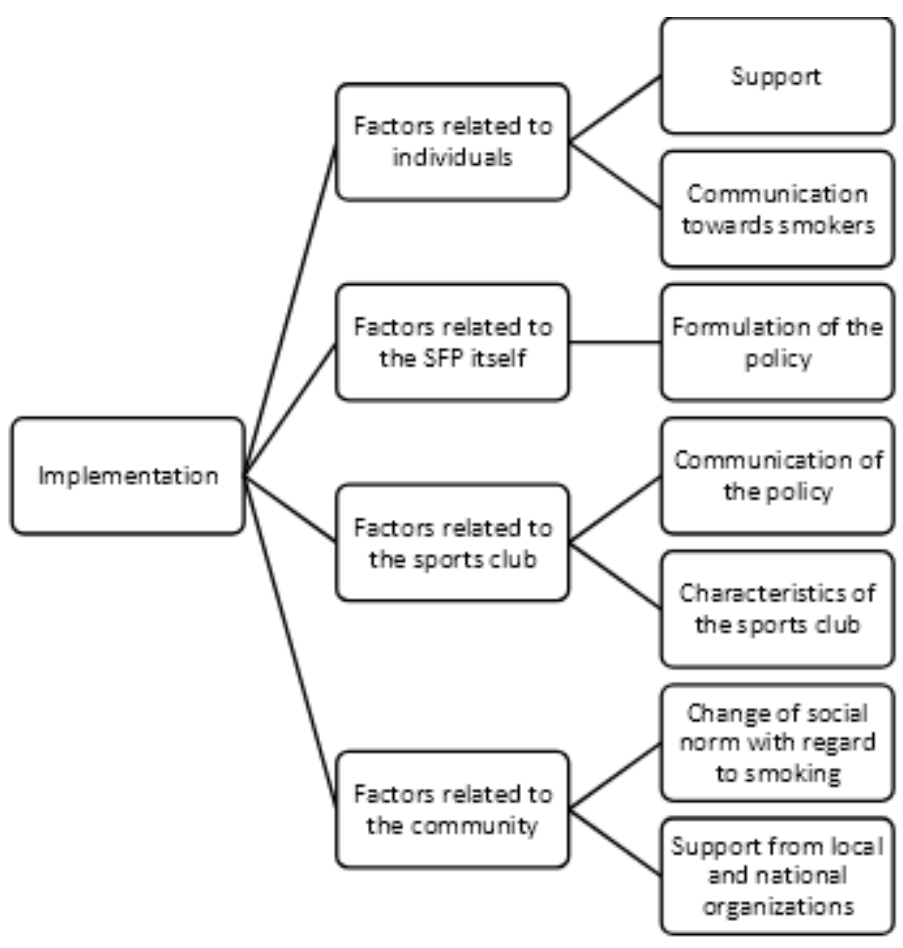

Figure 1

Factors that contribute to successful implementation

\section{Supplementary Files}

This is a list of supplementary files associated with this preprint. Click to download.

- SRQRchecklist.docx 